\title{
A Response to Covid-19: Recognizing Subcultures in the Unexpected Online Student Cohort
}

\author{
Angela J. Feekery ${ }^{1 *}$ and Shawn Michael Condon ${ }^{2}$ \\ ${ }^{1}$ School of Communication, Journalism and Marketing, Massey University, Palmerston North, New Zealand, ${ }^{2}$ School of \\ Communication, Journalism and Marketing, Massey University, Wellington, New Zealand
}

Keywords: COVID-19, first-year students experience, student engagement, interpersonal empathetic response, online learning, learner-focused pedagogy, international students, student subcultures

\section{INTRODUCTION}

In March 2020, the Aotearoa New Zealand (NZ) Government responded to Covid-19 by enacting a strict 4-week national lockdown, followed by a fortnight of partial restrictions (New Zealand Government, 2020). The pandemic dramatically impacted the education sector, moving all faceto-face teaching online. As one of the largest online education providers in NZ, our practices for engaging learners in disparate locations and meeting the varied cultural expectations of our diverse student population was put to the test.

Most courses at Massey University already had an established online programme; therefore, moving content online for internal students was not a major disruption. A common assumption was that internal students should easily transition to an online learning environment given we already deliver quality online education. However, on a course level, we recognized the domestic students new to tertiary education and offshore internal students could not be simply engaged in the same manner as experienced distance learners; due to student learning expectations, course design, and pedagogy style, merely shifting all learning online does not make capable online learners.

The objective of this paper is to share our insights gained from supporting three distinct student cohorts during lockdown, by focusing on their interpersonal needs as distinct subcultures within the broader student body. In our experience, a shift to online learning for students more comfortable in face-to-face teaching spaces requires decisions based more on pastoral than pedagogical concerns (particularly in a crisis situation) where robust blended learning spaces already exist.

University of Hradec Králové, Czechia

Reviewed by:

*Correspondence:

Angela J. Feekery

a.j.feekery@massey.ac.nz

Specialty section:

This article was submitted to

Culture and Communication,

a section of the journal

Frontiers in Communication

Received: 15 December 2020

Accepted: 16 March 2021

Published: 12 April 2021

Citation:

Feekery AJ and Condon SM (2021) A

Response to Covid-19: Recognizing

Subcultures in the Unexpected Online

Student Cohort.

Front. Commun. 6:642275.

doi: $10.3389 / f c o m m .2021 .642275$

\section{OUR UNIVERSITY CHANGES}

Our institution is branded as "New Zealand's leading university for distance learning" (Massey University, 2021). As the COVID-19 lockdown forced all learning online midway through the semester, university directives applied changes to all courses. Many of the interventions fitted within an emergency remote teaching approach, Hodges et al. (2020) explained as:

a temporary shift of instructional delivery to an alternate delivery mode due to crisis circumstances. It involves the use of fully remote teaching solutions for instruction or education that would otherwise be delivered face-to-face or as blended or hybrid courses and that will return to that format once the crisis or emergency has abated (para. 14).

Given the uncertainty and stress caused by the pandemic, teaching staff were aware of the increased cognitive load (maintaining attention on critically important public health messages, both intrinsic and extraneous work/life stressors, etc.) our students were experiencing. As such, university-mandated changes included: replacing exams with alternative assessments, removing compulsory coursework and sub-minima thresholds, granting extensions, and deferring study 
without financial penalty. Additionally, the mid-semester break was extended allowing teachers to prepare for online delivery and giving students time to adjust to lockdown without study pressures. We were instructed not to expect any students to complete assessments during this break nor to post any new material until the semester officially resumed.

\section{COURSE CHANGES}

The authors deliver a large, compulsory first-year business communication course to internal and distance students. For many of our students, this is their first experience in tertiary education and learning to cope with balancing the demands of work, life, and study.

The course uses a critical socio-constructive blended learning approach (Picciano, 2017) for all cohorts as they interact in course activities, and individual and collaborative assessments. A Learning Management System (LMS) is used to present weekly topics and materials for lectures and workshops, share information, submit assessments, and engage in general communication. Internal students have face-to-face lectures and workshops, while distance learners have pre-recorded lectures, synchronous online workshops, and fortnightly online office hours for direct communication with the course coordinator.

\section{SUBCULTURES IN OUR COHORT}

Semester 1, 2020, saw 660 students (380 distance and 280 internal) across two campuses representing three student subcultures the authors identified as having differing demographics, work situations, and learning experiences and expectations. Each subculture also has differing interpersonal and social needs relating to self-efficacy, emotions, belonging, and well-being (Kahu et al., 2020) that we considered when responding to the University's decision to shift all teaching online:

- Domestic distance students: Typically, mature students living in $\mathrm{NZ}$ or overseas studying online, mostly asynchronously, while working and/or raising families. For those attending synchronous workshops $(\sim 30 \%)$, sharing ideas through text chat was the preferred communication method. They frequently asked questions in forums, with peers responding and supporting each other outside staff office hours, creating a community of learning within the LMS and their peer-created social media spaces;

- Domestic internal students: Typically, university-age, transitioning to full-time study with synchronous face-to-face classes where interpersonal relationships are developed with staff and peers. They had limited experience of blended learning, but quickly learned to navigate the LMS. They rarely asked questions in forums, preferring to speak with tutors directly. In 2020, this cohort also included some early-arriving international students who found themselves somewhat isolated in student accommodation during lockdown;

- Offshore internal students: This is a new subculture of students that emerged in 2020. They were non-English speaking background (NESB) international students that usually study alongside domestic students on campus but were unable to come to NZ due to travel restrictions. Prior to 2020 , visa regulations disallowed international students from participating in online courses. Special governmental dispensations (NZQA, 2020) allowed international students to continue studying remotely. The offshore, predominantly Chinese cohort comprised two distinct groups. The first had previously studied at our University and were familiar with the LMS and ways of learning in NZ (however, they likely had limited prior experience studying wholly online). The second were newly enrolled in 2020 and 2021, with no experience of studying in NZ. These students engaged solely online and formed interpersonal relationships with teachers and peers in synchronous online workshops and through the course WeChat (a Chinese multi-purpose messaging, social media, and mobile payment app) forum.

With all three subcultures, effective communication to understand and meet student expectations is important especially in an online learning context. Research (Sander et al., 2000; Dell et al., 2010; Kahu et al., 2020) suggests that internal students have different expectations for learning than distance students. Dell et al. (2010) found students in modern learning contexts that utilize technology-supported blended learning had achievement and satisfaction rates similar to face-to-face and online learning experiences. Yet internal students tended to prefer engaging in face-to-face contact with teachers and peers, attending interactive lectures and tutorials, having synchronous discussions, receiving immediate feedback, and engaging in peer-supported learning (Sander et al., 2000; Kemp, 2020). Furthermore, NESB internal students want to experience cultural immersion and enhance their English language skills but may struggle with Western teaching and learning conventions (Li et al., 2002). Elgort et al. (2003) found NESB students report positive engagement with LMSs and online learning when teachers engage with them in this space. Choy et al. (2002) found "communication between teachers/facilitators and students is seen as the most critical factor in the success of a course; completion is partly attributable to students 'belonging' to the online community brought about through good communication" (p. 7). In summary, the different expectations of these subcultures informed the approaches adopted as we pivoted to a wholly online course delivery, as outlined in the next section.

\section{CHANGES IN COURSE DELIVERY}

We recognized student-teacher relationships in internal and distance learning spaces are formed and maintained quite differently. Therefore, rather than immersing internal subcultures into the existing distance learning spaces, we used LMS groupings to cater specifically to the needs of our domestic and offshore students, taking into account their technological, pedagogical, and social challenges, following Ferri et al. (2020) recommendations.

Recognizing the different subcultures, course staff implemented an interpersonal empathetic response (Lawson 
et al., 2019), which prompted us to consider, understand and validate students' feelings and concerns, listen to their needs, and provide flexibility for them to succeed. This approach enabled us to focus on maintaining student engagement throughout the lockdown and the remainder of the academic year as COVIDrelated uncertainty became the norm. The varied needs of each subculture were met through adopting different technologies and establishing a system of individualized support. While many students returned when the semester resumed, we found it necessary to reengage some with additional communication. The volume of assessment-related questions also increased as students were missing key information by not attending or watching workshop recordings where key information was shared and explored. This was the biggest workload challenge for course staff, alongside the increased administrative workload.

In the next three sections, we provide a brief overview of the key changes implemented to meet the academic and pastoral (advice and practices focused on student well-being) needs of each distinct subculture.

\section{DOMESTIC DISTANCE STUDENTS}

The domestic distance cohort remained largely unchanged in terms of course delivery. However, for many, their work and personal lives drastically changed. Many had job insecurity or increased workload (essential workers) and/or found themselves with children at home, trying to balance work, study, and home-schooling. Stress was particularly high among this group. Therefore, our primary interventions centered on their wellbeing as they navigated change, namely:

1. monitoring engagement in the LMS and assignment submission;

2. proactively reaching out when we observed limited course engagement or non-submission of assessments and offering flexible extensions.

This approach aligns with advice regarding capturing students in the "zone of discontent" (Jeffrey et al., 2012); that is, when students exhibit behaviors such as non-engagement, teachers implement interventions to encourage and support them to reengage before they take the irreversible step of withdrawing. Students in this category identified through LMS analytics were emailed to ask what support would enable them to complete the course. Regular notifications were also posted in the forum encouraging those struggling to seek advice and support.

\section{DOMESTIC INTERNAL STUDENTS}

For the domestic internal cohort, the method of engagement needed to pivot quickly to an all-digital offering. We could not simply transition these students, accustomed to face-toface pedagogy, to distance learning methods. These students had already established interpersonal relationships with their tutors and peers prior to the lockdown. In the initial days of lockdown, the primary focus of course staff was maintaining these relationships. We provided targeted support for students transitioning to become wholly online learners, though using the LMS for finding information, accessing learning materials and submitting assessments was already familiar. We transitioned these students into the existing structures for distance students using:

1. pre-recorded, streaming lectures;

2. live workshops with their current tutors;

3. extended online office hours by appointment;

4. an exclusive forum for communication.

When study resumed, we focused on familiarizing students with expectations for online learners, such as more frequent engagement with the LMS for both communication and learning activities and a greater degree of self-directed learning (Kahu et al., 2020). Initially attendance was low, and "live" attendance remained limited. We quickly realized further communication was needed to encourage these students to continue engaging with the course. Students who had not accessed the course within a week of the semester resuming were offered additional support though direct communication from course staff and through referrals to student support offices.

\section{OFFSHORE INTERNAL STUDENTS}

To establish online learning spaces for our offshore students, some of whom had not experienced learning in the NZ context, it was critical for course staff to familiarize them with learning in the LMS environment and acclimatizing to a foreign culture and pedagogies. We could not implement the same online tools the domestic internal students were using, as the Chinese government maintains strict policies about software use within their borders, controlled by "the Great Firewall" (Lau, 2020). This meant no access to Adobe products or the University's online streaming service and prohibited use of all Google services, including access to Google Docs, Drive and Gmail, and Google Search and YouTube, which students frequently use when conducting research for assessments. To facilitate a smooth transition, course staff:

1. created an "offshore students" LMS page and dedicated communication forum specific to their needs;

2. adopted WeChat channel, with direct, regular communication to all students in the cohort;

3. made recorded lectures directly downloadable;

4. conducted weekly, synchronous Zoom workshops taught by the same tutor to allow student-teacher interpersonal relationships to evolve and were recorded for those unable to attend in-person.

In order to maximize their participation, only offshore internal students were in this group. Finding their voice and expressing their opinions in face-to-face classes alongside native English speakers proves challenging enough (Hsu and Huang, 2017); expecting the same in a virtual classroom could be intimidating. Since these students had not yet built relationships with their domestic peers, nor experienced strategies teachers use to encourage participation, we felt it more beneficial to have 
workshops solely for them. Nevertheless, they tended to remain passive observers. Therefore, in semester 2, a Mandarinspeaking tutor was enlisted to facilitate conversations in their native tongue, alongside the English-language curriculum. For groupwork, we created teams of students based only in China, so they could engage with each other using the technologies available to them.

\section{CONCLUDING THOUGHTS}

Shifting to wholly online learning meant careful consideration of our three cohorts' subcultures and tailoring support and engagement differently. For course staff, flexibility and increased communication became the norm. Awareness of the unique subcultures within our broader student cohort meant we could respond more personally and empathetically to the individual needs of $600+$ students.

The domestic distant students, largely self-directed, continued studying in familiar ways without any major changes; however, a significant increase in pastoral care and communication was needed. Additional support focused on well-being, implemented through extended deadlines and increased communication as we monitored engagement and proactively reached out to those we perceived were falling behind.

\section{REFERENCES}

Choy, S., McNickle, C., and Clayton, B. (2002). Learner Expectations and Experiences. An Examination of Student Views of Support in Online Learning. Australian National Teaching Authority. Available online at: https://ncver.edu. $\mathrm{au} /$ research-and-statistics/publications/all-publications/learner-expectationsand-experiences-an-examination-of-student-views- of-support-in-onlinelearning

Dell, C. A., Low, C., and Wilker, J. F. (2010). Comparing student achievement in online and face-to-face class formats. J. Online Learn. Teach. 6, 30-42.

Elgort, I., Marshall, S., and Mitchell, G. (2003). "NESB student perceptions and attitudes to a new online learning environment," in Learning for an Unknown Future: Proceedings of the 2003 Annual International Conference of the Higher Education Research and Development Society of Australasia (HERDSA), 6-9 July, Christchurch, New Zealand, Vol. 26, eds H. Mathews and R. McKay (Milperra, NSW: Higher Education Research and Development Society of Australasia).

Ferri, F., Grifoni, P., and Guzzo, T. (2020). Online learning and emergency remote teaching: opportunities and challenges in emergency situations. Societies 10, 86-104. doi: 10.3390/soc10040086

Hodges, C., Moore, S., Lockee, B., Trust, T., and Bond, A. (2020). The Difference Between Emergency Remote Teaching and Online Earning. Available online at: https://er.educause.edu/articles/2020/3/the-difference-betweenemergency-remote-teaching-and-online-learning

Hsu, C., and Huang, I. (2017). Are international students quiet in class? The influence of teacher confirmation on classroom apprehension and willingness to talk in class. J. Inte. Stud. 7, 38-52. doi: 10.32674/jis.v7i1.244

Jeffrey, L. M., Milne, J., Suddaby, G., and Higgins, A. (2012). Help or Hindrance: Blended Approaches and Student Engagement. AKO Aotearoa Research Report. Available online at: https://ako.ac.nz/assets/Knowledge-centre/NPF09-041-Help-or-Hindrance-Blended-approaches-and-student-engagement/ RESEARCH-REPORT-Help-or-Hindrance-Blended-Approaches-andStudent-Engagement.pdf

Kahu, E. R., Picton, C., and Nelson, K. (2020). Pathways to engagement: a longitudinal study of the first-year student experience in the educational interface. Higher Educ. 79, 657-673. doi: 10.1007/s10734-019-00429-w
For the internal cohorts, we adopted key strategies to meet online learning expectations guided by our experience teaching of distance learners, while recognizing the unique subcultures with different learning needs in an online learning space. The two internal subcultures required different engagement methods for workshop delivery, interpersonal relationship development and maintenance and communication. Though this increased workload for course staff, course feedback indicated students felt supported throughout this challenging semester and most completed the course successfully, with a comparison of 2019 and 2020 showing overall pass rates for the course as 80.8 and $81.25 \%$, respectively.

At present, our offshore students are continuing to study online and our internal students have returned to campus for small-group workshops. Applying the lessons learned in 2020 , we are well-prepared to revert quickly to online teaching for our internal student subcultures, should future need arise.

\section{AUTHOR CONTRIBUTIONS}

All authors listed have made a substantial, direct and intellectual contribution to the work, and approved it for publication.

Kemp, N. (2020). University students' perceived effort and learning in face-to-face and online classes. J. Appl. Learn. Teach. 3, 69-77. doi: $10.37074 /$ jalt.2020.3.s1.14

Lau, J. (2020,. April 16). China's Limitations on Distance Education. Available online at: https://www.insidehighered.com/news/2020/04/16/chinese-limitsinternet-complicate-distance-education

Lawson, C., Gill, R., Feekery, A., and Witsel, M. (2019). Communication Skills for Business Professionals. Cambridge, MA: Cambridge University Press. doi: $10.1017 / 9781108594349$

Li, M., Baker, T., and Marshall, K. (2002). Mismatched expectations: a case study of Asian students in New Zealand. N. Zeal. J. Appl. Business Res. 1, 137-156.

Massey University (2021). Study by Distance. Available online at: https://www. massey.ac.nz/massey/explore/study/distance/distance_home.cfm

New Zealand Government (2020). COVID-19 Alert System. Available online at: https://covid19.govt.nz/alert-system/

NZQA (2020). Validation of Temporary Approvals for Programmes Delivered by Distance Offshore Online. Available online at: https:/www.nzqa.govt.nz/assets/ About-us/News/COVID-19/Temporary-programme-validation-processOffshore-online.pdf

Picciano, A. G. (2017). Theories and frameworks for online education: seeking an integrated model. Online Learn. 21, 166-190. doi: 10.24059/olj.v21i3.1225

Sander, P., Stevenson, K., King, M., and Coates, D. (2000). University students' expectations of teaching. Stud. Higher Educ. 25, 309-323. doi: 10.1080/0307507005019 3433

Conflict of Interest: The authors declare that the research was conducted in the absence of any commercial or financial relationships that could be construed as a potential conflict of interest.

Copyright (c) 2021 Feekery and Condon. This is an open-access article distributed under the terms of the Creative Commons Attribution License (CC BY). The use, distribution or reproduction in other forums is permitted, provided the original author(s) and the copyright owner(s) are credited and that the original publication in this journal is cited, in accordance with accepted academic practice. No use, distribution or reproduction is permitted which does not comply with these terms. 